\title{
Assessment of Patient Satisfaction with Nursing Care in Selected Wards of the Lagos University Teaching Hospital (Luth)
}

\author{
Olowe A Folami F* and Odeyemi 0
}

Department of Nursing, Nigeria

*Corresponding author: FF Folami, Department of Nursing, Nigeria

\begin{abstract}
ARTICLE INFO
Received: 幽 April 01, 2019

Published: April 15, 2019

Citation: Olowe A F F, Odeyemi 0. Assessment of Patient Satisfaction with Nursing Care in Selected Wards of the Lagos University Teaching Hospital (Luth). Biomed J Sci \& Tech Res 17(1)-2019. BJSTR. MS.ID.002941.
\end{abstract}

Keywords: Patient Satisfaction; Nursing Care; Quality of Care; Nursing Practice
ABSTRACT

Health care is changing rapidly and the need to improve quality in its delivery is increasing. Patient satisfaction is a central indicator for health care quality and reflects the ability of the provider to meet the patients' needs. The most important predictor of patient's overall satisfaction with hospital care is particularly related to their satisfaction with nursing care. This study assessed patient satisfaction with nursing care in selected wards of the Lagos University Teaching Hospital (LUTH). Jean Watson's theory of human caring was used to form the theoretical foundation for this study due to its emphasis on the caring process and the relationship between the nurse and the patient. A convenient nonprobability sampling technique was employed for the study. The sample size was estimated using the total enumeration method. Data was collected by means of questionnaires. A total of 120 questionnaires were distributed with $100 \%$ return rate. The findings revealed that only $77 \%$ of the patients showed excellent satisfaction with the quality of nursing care received during their stay on the ward. It is recommended that patient suggestions for improving the quality of nursing care should be implemented and annual continuous educational program on patient satisfaction should be mandatory for all nurses.

\section{Introduction}

Health care is changing rapidly and the need to improve quality in its delivery is increasing. Patient satisfaction is a central indicator for health care quality and reflects the ability of the provider to meet the patients' needs [1]. Patient satisfaction is defined as the extent of the resemblance between the expected quality of care and the actual received care. Patient satisfaction with nursing care is of great importance to any health care agency because nurses comprise most health care providers and they provide care for patients 24 hours a day [2]. Patients are easier to serve if they feel their needs are being met. Patient satisfaction has been used as an indicator of quality services provided by health care personnel in tertiary hospitals. The most important predictor of patient's overall satisfaction with hospital care is particularly related to their satisfaction with nursing care [3] Studies of the quality of nursing care are increasing in importance as a component of health care research. The consumer's appraisal of services is being considered in assessments of quality. Thus, evaluating the quality of nursing care involves the measurement of its benefits to patients and the society at large [4] Assessing to what extent patients are satisfied with health services is clinically relevant, as satisfied patients are more likely to comply with treatment, take an active role in their own care, to continue using medical care services and stay within a health provider (where there are some selections to be made) and maintain with a specific system [5]. Consequently, the nurse patient relationship has a powerful impact on patient satisfaction.

Patient's satisfaction is now a critical variable in any calculation of quality or value and therefore in the assessment of corporate/ individual accountability. It is a reliable and essential measure of quality of care [6]. The greater focus on patient satisfaction has meant a shift away from depending solely on clinical outcomes such as pressure ulcers, falls, mortality, and morbidity and this has led to a need for more research on the other components of patient satisfaction [7]. Patient satisfaction is one of the ultimate's validates of effectiveness and quality of care as the patient's opinion of the 
care received from nursing staff who working in hospitals with care services [8]. Given this link between patient satisfaction and quality nursing care, it is not surprising to learn that patient satisfaction is generally found to be high in organizations where there are good relationships between nurses and patients [9]. This demonstrated importance has made satisfaction with nursing care a critical issue in today's competitive health care environment, which places a premium on demonstrated effectiveness and public accountability [3]. However, few studies have specifically been done on opinion of patients on their hospital experiences. In response, this study assessed patient satisfaction with nursing care in selected wards of the Lagos University Teaching Hospital (LUTH).

The study also compared patient satisfaction with nursing care in different selected wards and measure overall satisfaction with nursing care in selected wards of the hospital. Patient satisfaction has gained the attention from global scholars. Researches in the developed countries such as United States (US), United Kingdom (UK) and Canada have pointed out the importance of patients' satisfaction as the core quality indicator, particularly in the area of nursing care [10]. Nurses are the frontline people that patients most likely meet up with, spend the highest amount of time with and rely upon for recovery during their hospitalization. Nursing care plays a prominent role in determining the overall satisfaction of patients hospitalization experience [3]. Assessing patient satisfaction with nursing care is important in evaluating whether patients' needs are fulfilled and subsequently facilitating in the planning as well as implementing appropriate nursing interventions for patients. Determining factors contribute most to patient satisfaction can further assist nurses in improving the quality of nursing care. Hence, patient satisfaction with nursing care is an imperative determinant of quality of care particularly in the clinical/ healthcare facility settings [11]. In the marketing perspectives, patient satisfaction is considered as the intermediary between patients' perspectives of service quality and future intention of re-using or commending the healthcare service [12].

\section{Patient Satisfaction}

Patient's satisfaction is a person's feeling of pleasure or disappointment resulting from a service's perceived performance or outcome in relation to his or her expectations. As this definition makes it clear, satisfaction is a function of perceived performance and expectations. [13] conducted a cross sectional study in 1100 bed hospital in Turkey. The aim of the study was to assess patient satisfaction with nursing care and relationship between patient characteristics. The study was conducted between February and September 2006 within 12 different services in the Hospital, each with a 20-25 bed capacity and 6-7 nurses. Seven internal medicine wards and 5 surgical wards were included in the study. Twohundred-and twenty-nine adult patients (98 surgical, 131 medical) recruited to the study. The participants who were eligible for recruitment were patients of at least 18 years of age who had been hospitalized for at least 2 days were due to be discharged.

Data were collected using the Newcastle satisfaction with nursing care scale and a patient information form. Overall data indicated a high level of patient satisfaction. Hospitalization affected the Experience of Nursing Care Scale independently, while the type of ward, sex, income, and education independently affected the satisfaction with Nursing Care Scale. Patient who underwent surgical procedures, male patients, the 40-59-year-old age group those who had low levels of education or income, and patients who were hospitalized for longer periods were most satisfied. Patients age, sex, income, ward type were important factors that affected their satisfaction with nursing care.

\section{Patient Satisfaction and Quality of Care}

Patients should be allowed to define their own priorities and evaluate their care accordingly, rather than having those criteria selected by professionals. Satisfaction studies can function to give providers some idea of care how they would have to modify their provision of services in order to make their patients more satisfied. The extent to which consumer opinion can influence policy makers and health care personnel is not only dependent upon collecting the right kind of data, it also requires that policy makers and health personnel accept the value of the consumer's point of view. Consumer Satisfaction studies can be used for three related but distinct purposes: as evaluations of the quality of care, as outcome variables, and as indicators of which aspects of a service need to be changed to improve patient response [14].

[15] conducted a descriptive study was to determine helpless patients" satisfaction with quality of care received at tertiary hospitals in Enugu in Nigeria. Total populations of 105 helpless patients, those that need assistance with the activities of daily living were studied. Tools for data collection were questionnaire and interview guide. Data were analyzed using descriptive statistics. Results showed that helpless patients were satisfied with physical and psychological care but satisfaction with spiritual care was marginal. Nurses seemed to lack skills for meeting spiritual needs of the patients. Patients' satisfaction with nurses' attitude was marginally positive. The study showed that there was need for improvement in the care nurses provide for helpless patients in the spiritual dimension.

\section{Nursing Care and Patient Satisfaction}

Patient satisfaction with nursing care is considered an important factor in explaining patients' perceptions of service quality. The patient's perspective is increasingly being viewed as a meaningful indicator of health services quality and may, in fact, represent the most important perspective [16]. A research study was conducted in Sweden using a prospective, descriptive survey, to identify patient's perceptions of quality of care at an emergency department and areas for quality improvement [17]. Study design was adopted, and the study took place in one emergency department at a Swedish university hospital in 2002. The participants were 99 women and 101 men, with an average age of 51 years. The emergency department version of the questionnaire Quality from the Patient's Perspective was used for data collection. The result of the study was patients estimated quality of care at the emergency department as fairly good, but there were areas in need of improvement. A high percent of inadequate quality was related to the environment in the emergency department. About $20 \%$ of patients reported that they did not receive effective pain relief. More than $20 \%$ estimated that 
nurses did not show an interest in their life situation and patients did not receive useful information on self - care and about which physician was responsible for their medical care.

[18] conducted a study on Nursing care quality and adverse events in US hospitals, to examine the association between nurses' reports of unmet nursing care needs and their reports of patients' receipt of the wrong medication or dose, nosocomial infections and patient falls with injury in hospitals. Secondary analysis of crosssectional data collected in 1999 from 10,184 staff nurses and 168 acute care hospitals in the US. The proportion of necessary nursing care left undone ranged from $26 \%$ for preparing patients and families for discharge to as high as $74 \%$ for developing or updating nursing care plans. Most nurses reported that patients received the wrong medication or dose, acquired nosocomial infections, or had a fall with injury infrequently. The adverse events occurred frequently varied considerably [i.e. medication errors (15\%), patient falls with injury (20\%), nosocomial infection (31\%)]. After adjusting for patient factors and the care environment, there remained a significant association between unmet nursing care needs and each adverse event.

\section{Applications of the Theory}

Jean Watson's Theory on Human Caring can be used as a guide and applied to many different aspects of nursing [19]. Caring is one of the fundamental pillars of nursing [20]. When caring behavior is not portrayed in patient care, it may generate negative perception in healthcare delivery and this in turn affects patient satisfaction with nursing care [21]. Jean Watson's theory of human caring was used to form the theoretical foundation for this study due to its emphasis on the caring process and the relationship between the nurse and the patient.

\section{Method}

The research was carried out in Lagos University Teaching Hospital (LUTH), Idi-Araba, Lagos State. It was founded and established in the year 1912 in the outskirts of Surulere, Lagos in Mushin Local Government Area. It bond on the North by Agege

\section{Presentation of Results}

\section{Socio-Demographic Characteristics}

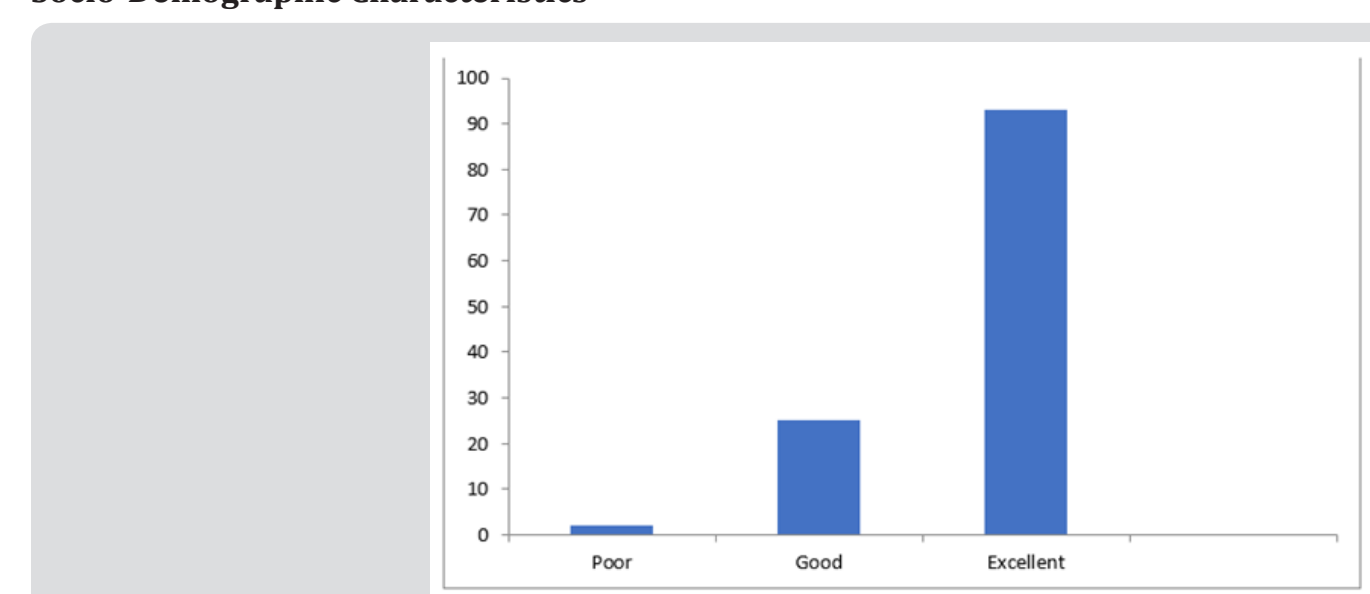

Figure 1: Bar diagram showing patient level of satisfaction with quality of nursing care.
Motor road, on the south by Ishaga road. The targeted populations of this study were male and female in-patients in the selected of the hospital. A convenient non-probability sampling technique employed for the study. The sample size was estimated using the total enumeration method, which means that the total population of the selected wards were used, aged eighteen and above. Each wards having a total of 30 patients.

\section{Data Collection}

Data was collected by means of questionnaires which were administered to eligible participants after obtaining permission from the chief nursing officers of each selected ward. Respondents were briefed on the purpose of the study before they are asked to fill in their responses to the questionnaire as appropriate.

\section{Instrument for Data Collection}

The data collection questionnaire was self-administered, and it comprises close-ended, open-ended, multiple choice questions divide into four sections as follows:

\section{Section A: Demographic Data}

Section B: Patients' satisfaction with quality of nursing care in medical wards

Section C: Patients' satisfaction with different dimensions of nursing care

Section D: Patients' overall satisfaction with nursing care in medical wards

\section{Ethical Consideration}

Permission to collect data was received from the ethical committee of the Lagos University Teaching Hospital. Details of the study were explained verbally, and informed consent was obtained from all participants before their participation in the study. Participants received assurance of confidentiality. Permission sought from all the chief nursing officers of the selected wards beforehand. 
A total of 120 standard questionnaires were distributed among patients in the wards of LUTH Idi-araba Lagos. All 120 questionnaires were administered successfully and were adequate for analysis. Sixty $(50 \%)$ of the participants were female while the other sixty $(50 \%)$ were male with ages ranging from 21-80 years. Eighty-two $(63.3 \%)$ were married, three $(2.5 \%)$ were separated, thirty-one $(25.8 \%)$ were single while four $(3.4 \%)$ were widowed. Majority of the respondents, sixty-seven (55.8\%) were from the ethnic group Yoruba followed by the Igbos which comprised thirty-four $(28.3 \%)$ of the respondents, two $(1.7 \%)$ of the respondents were Hausa while the remaining seventeen (14.2\%) participants were from Table 1: Socio-demographic Characteristics of Respondents. other ethnic groups. Their level of satisfaction was scored using a likert scale. Excellent was given a score of 5 . Very good was given a score of 4 . Good was given a score of 3 . Fair was given a score of 2 . Poor was given a score of 1 . Respondents with scores less than 27.5 have poor satisfaction, respondents with scores between 27.5 and below 38.5 have good satisfaction, and respondents with scores of 38.5 and above have excellent satisfaction. Table 1 shows patient level of satisfaction with quality of nursing care. Only 1.7\% rated poor, $25(25.8 \%)$ rated good and $93(77.5 \%)$ rated their satisfaction with quality of care as excellent (Figure 1, Tables 1-3).

\begin{tabular}{|c|c|c|}
\hline Variable $(n=120)$ & Frequency & Percentage (\%) \\
\hline \multicolumn{3}{|c|}{ Age group (years) } \\
\hline $21-30$ & 16 & 13.3 \\
\hline $31-40$ & 32 & 26.7 \\
\hline $41-50$ & 35 & 29.2 \\
\hline $51-60$ & 20 & 16.7 \\
\hline $61-70$ & 10 & 8.3 \\
\hline $71-80$ & 7 & 5.8 \\
\hline \multicolumn{3}{|c|}{ Gender } \\
\hline Male & 60 & 50.0 \\
\hline Female & 60 & 50.0 \\
\hline \multicolumn{3}{|c|}{ Marital status } \\
\hline Married & 82 & 68.3 \\
\hline Separated/divorced & 3 & 2.5 \\
\hline Single & 31 & 25.8 \\
\hline Widowed & 4 & 3.4 \\
\hline \multicolumn{3}{|c|}{ Ethnicity } \\
\hline Hausa & 2 & 1.7 \\
\hline Igbo & 34 & 28.3 \\
\hline Yoruba & 67 & 55.8 \\
\hline Others & 17 & 14.2 \\
\hline
\end{tabular}

Table 2: Medical History Of Respondents.

\begin{tabular}{|c|c|c|}
\hline Variables $(n=120)$ & Frequency & Percentage $\%$ \\
\hline \multicolumn{3}{|c|}{ Including this most recent hospital stay, } \\
\hline \multicolumn{3}{|c|}{ how many times were you (the patient)? } \\
\hline \multicolumn{3}{|c|}{ hospitalized in the past 2 years } \\
\hline Only once & 56 & 46.7 \\
\hline Twice & 46 & 38.2 \\
\hline 3 times & 14 & 11.7 \\
\hline 4 times & 2 & 1.7 \\
\hline Over 4 times & 2 & 1.7 \\
\hline \multicolumn{3}{|c|}{ Overall, how would you rate your (the patient's) } \\
\hline \multicolumn{3}{|c|}{ Health before this most recent hospital stay } \\
\hline Excellent & 29 & 24.2 \\
\hline Good & 49 & 40.8 \\
\hline Fair & 26 & 21.7 \\
\hline
\end{tabular}




\begin{tabular}{|c|c|c|}
\hline Poor & 12 & 10.0 \\
\hline Very Poor & 3 & 2.5 \\
\hline Unsure & 1 & 0.8 \\
\hline \multicolumn{3}{|c|}{ Were you? } \\
\hline Admitted through the emergency department & 47 & 39.2 \\
\hline Transferred from another facility & 46 & 38.3 \\
\hline Admitted through patient registration/to the unit directly & 17 & 14.2 \\
\hline Admitted after day procedure or test & 4 & 3.3 \\
\hline Other & 6 & 5.0 \\
\hline \multicolumn{3}{|c|}{ For most of your hospital stay, were you in a room } \\
\hline By yourself & 1 & 0.8 \\
\hline With 1 other person & 0 & 0.0 \\
\hline With more than 1 person & 119 & 99.2 \\
\hline Total & 120 & 100 \\
\hline
\end{tabular}

Table 3: Patient satisfaction with quality of nursing care.

\begin{tabular}{|c|c|c|c|c|c|}
\hline Variable(n=120) & Excellent & Very good & Good & Fair & Poor \\
\hline $\begin{array}{l}\text { How clear and complete were the Nurses explanations } \\
\text { about tests, Treatments and what to expect }\end{array}$ & $6(5.0 \%)$ & $52(43.3 \%)$ & $45(37.5 \%)$ & $16(13.3 \%)$ & $1(0.9 \%)$ \\
\hline $\begin{array}{l}\text { How well nurses explained how to prepare for tests } \\
\text { and operations }\end{array}$ & $5(4.2 \%)$ & $45(37.5 \%)$ & $43(35.8 \%)$ & $26(21.7 \%)$ & $1(0.8 \%)$ \\
\hline How willing were the nurses to answer your questions & $12(10.0 \%$ & $58(48.3 \%)$ & $42(35.0 \%)$ & $8(6.7 \%)$ & $0(0.0 \%)$ \\
\hline $\begin{array}{l}\text { How well did nurses communicate with your family } \\
\text { and doctors }\end{array}$ & $10(8.4 \%$ & $78(65.0 \%)$ & $28(23.3 \%)$ & $4(3.3 \%)$ & $0(0.0 \%)$ \\
\hline $\begin{array}{l}\text { How well did the nurses keep them informed about } \\
\text { your conditions and needs }\end{array}$ & $16(13.3 \%$ & $69(57.5 \%)$ & $33(27.5 \%)$ & $2(1.7 \%)$ & $0(0.0 \%)$ \\
\hline How much they were allowed to help in your care & $26(21.7 \%)$ & $65(54.2 \%)$ & $28(23.3 \%)$ & $1(0.8 \%)$ & $0(0.0 \%)$ \\
\hline How friendly and kind were the nurses to you & $26(21.7 \%)$ & $59(49.1 \%)$ & $33(27.5 \%)$ & $2(1.7 \%)$ & $0(0.0 \%)$ \\
\hline $\begin{array}{l}\text { How often did the nurses check on you and keep track } \\
\text { of how you were doing }\end{array}$ & $24(20.0 \%)$ & $57(47.5 \%)$ & $36(30.0 \%)$ & $3(2.5 \%)$ & $0(0.0 \%)$ \\
\hline $\begin{array}{l}\text { How much did the nurses ask you what you think and } \\
\text { give you choices }\end{array}$ & $6(5.0 \%)$ & $21(17.5 \%)$ & $63(52.5 \%)$ & $26(21.7 \%)$ & $4(3.3 \%)$ \\
\hline $\begin{array}{c}\text { How willing the nurses to be flexible in meeting your } \\
\text { needs }\end{array}$ & $5(4.2 \%)$ & $43(35.8 \%)$ & $50(41.7 \%)$ & $17(14.1 \%)$ & $5(4.2 \%)$ \\
\hline $\begin{array}{l}\text { How well did they adjust their schedules to your } \\
\text { needs }\end{array}$ & $6(5.0 \%)$ & $50(41.7 \%)$ & $33(27.5 \%)$ & $18(15.0 \%)$ & $13(10.8 \%)$ \\
\hline
\end{tabular}

The level of satisfaction was scored using a likert scale. Excellent was given a score of 5 . Very good was given a score of 4. Good was given a score of 3. Fair was given a score of 2. Poor was given a score of 1 . Respondents with scores less than 17.5 have poor satisfaction, respondents with scores between 17.5 and below 24.5 have good satisfaction, and respondents with scores of 24.5 and above have excellent satisfaction. Table 4 shows patient satisfaction with dimensions of nursing care. $9(7.5 \%)$ rated poor, $65(54.2)$ rated good while $46(38.3 \%)$ rated their satisfaction with dimensions of nursing care as excellent (Figure 2, Table 5). The level of satisfaction was scored using a likert scale. Excellent was given a score of 5 . Very good was given a score of 4 . Good was given a score of 3. Fair was given a score of 2. Poor was given a score of 1 . Strongly agree was given a score of 5 . Somewhat agree was given a score of 4 . Agree was given a score of 3 . Somewhat disagree was given a score of 2. Strongly disagree was given a score of 1 . Respondents with scores less than 10 have poor satisfaction, respondents with scores between 10 and below 14 have good satisfaction, and respondents with scores of 14 and above have excellent satisfaction. Table 5 shows the overall level of patient satisfaction among patients in medical wards of LUTH. $0.9 \%$ rated satisfaction as poor, $30.8 \%$ rated satisfaction as good while the majority $(65.3 \%)$ rated their satisfaction as excellent (Figure 3). 


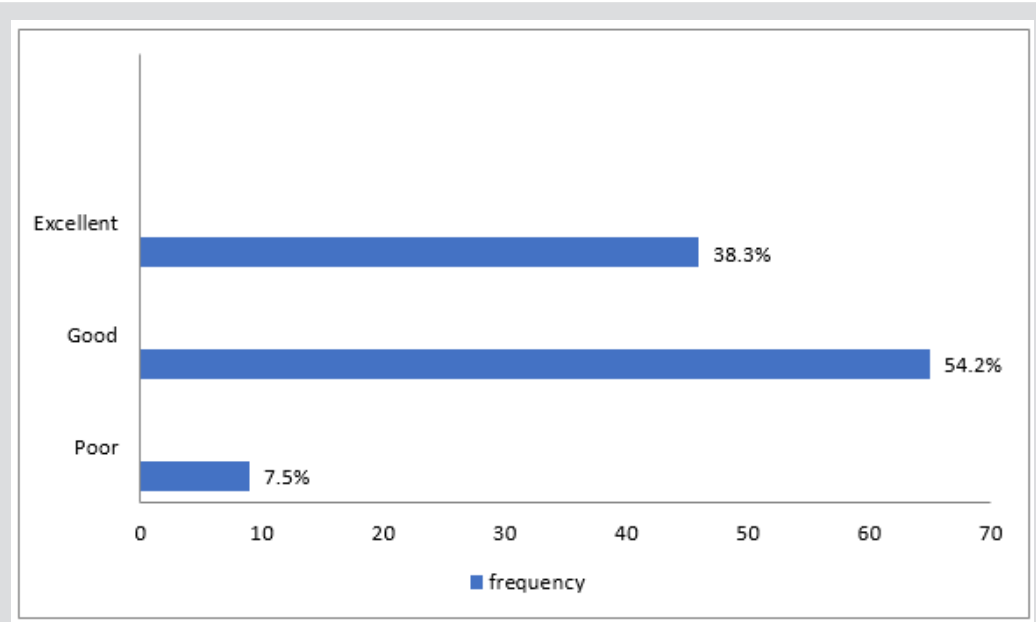

Figure 2: Bar diagram showing patient satisfaction with dimensions of nursing care.

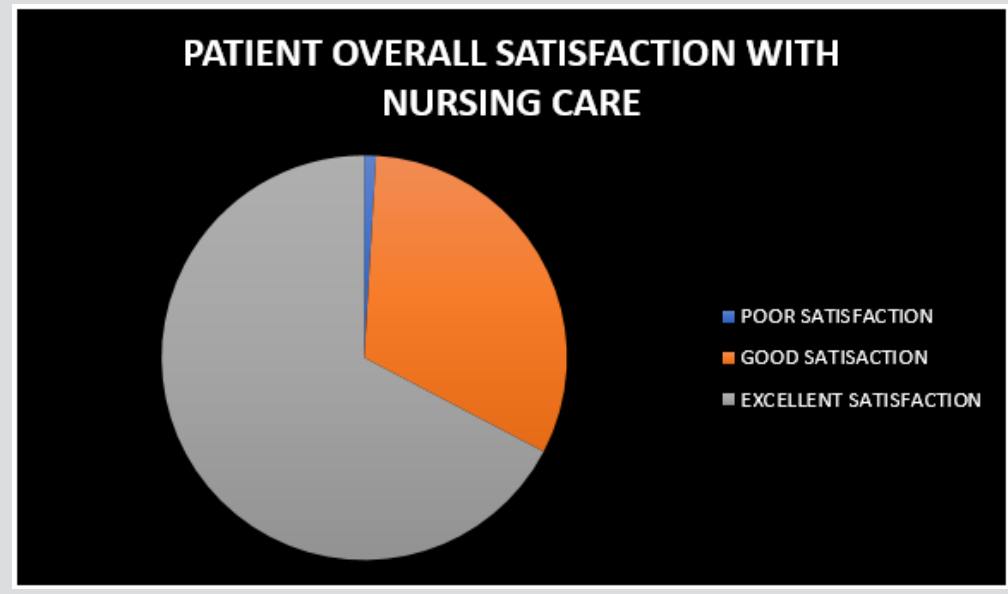

Figure 3: Patient overall level of satisfaction with nursing care in medical wards of LUTH.

Table 4: Patient Satisfaction with Dimensions of Nursing Care.

\begin{tabular}{|c|c|c|c|c|c|}
\hline Variable $(n=120)$ & Excellent & Very good & Good & Fair & Poor \\
\hline Helpfulness & $9(7.5 \%)$ & $63(52.5 \%)$ & $43(35.8 \%)$ & $5(4.2 \%)$ & $0(0.0 \%)$ \\
\hline Nursing staff response time & $11(9.2 \%)$ & $82(68.3 \%)$ & $22(18.3 \%)$ & $5(4.2 \%)$ & $0(0.0 \%)$ \\
\hline Skill and Competence of Nurses & $25(20.8 \%)$ & $73(60.8 \%)$ & $19(15.8 \%)$ & $2(1.7 \%)$ & $1(0.8 \%)$ \\
\hline Restful Atmosphere Provided by Nurses & $33(27.5 \%)$ & $50(41.7 \%)$ & $33(27.5 \%)$ & $4(3.3 \%)$ & $0(0.0 \%)$ \\
\hline Privacy & $15(12.5 \%)$ & $35(29.2 \%)$ & $44(36.7 \%)$ & $23(19.1 \%)$ & $3(2.5 \%)$ \\
\hline Giving of Discharge Instructions & $8(6.7 \%)$ & $15(12.5)$ & $36(30.0 \%)$ & $38(31.7 \%)$ & $23(19.1 \%)$ \\
\hline Coordination of care after discharge. & $3(2.5 \%)$ & $4(3.3 \%)$ & $15(12.5 \%)$ & $33(27.5 \%)$ & $65(54.2 \%)$ \\
\hline
\end{tabular}

Table 5: Patient Overall Satisfaction with Nursing Care.

\begin{tabular}{|c|c|c|c|c|c|}
\hline Variable(n=120) & Excellent & Very good & Good & Fair & Poor \\
\hline $\begin{array}{c}\text { Overall quality of care and services you received during your } \\
\text { hospital stay }\end{array}$ & $9(7.5 \%)$ & $58(48.3 \%)$ & $49(40.9 \%)$ & $4(3.3 \%)$ & $0(0.0 \%)$ \\
\hline $\begin{array}{c}\text { Overall quality of nursing care you received during your hospital } \\
\text { stay }\end{array}$ & $10(8.3 \%)$ & $67(55.8 \%)$ & $42(35.0 \%)$ & $1(0.9 \%)$ & $0(0.0 \%)$ \\
\hline In general, would you say your health is & $14(11.7 \%)$ & $51(42.5 \%)$ & $51(42.5 \%)$ & $4(3.3 \%)$ & $0(0.0 \% 0$ \\
\hline
\end{tabular}




\section{Discussion of Results}

\section{Socio-Demograhic Characteristics}

Fifty percent of the respondents were female, and fifty percent of the respondents were male this is in similitude with a study carried out in China to develop an understanding of caring in nursing in which fifty per of the respondents were male and fifty percent were female22. The age range of participants was between 21 and 80 years which are in consonance with a study done by Gurdogan, Findik and Arslam (2014) in which the age of participants ranged from 18 to 80 years. Eighty-two (63.3\%) were married, three $(2.5 \%)$ were separated, thirty-one (25.8\%) were single while four $(3.4 \%)$ were widowed. Majority of the respondents, sixty-seven (55.8\%) were from the ethnic group Yoruba followed by the Igbos which comprised thirty-four $(28.3 \%)$ of the respondents, two $(1.7 \%)$ of the respondents were Hausa while the remaining seventeen $(14.2 \%)$ participants were from other ethnic groups.

\section{Assessing Patients' Satisfaction with Quality of Nursing}

\section{Care}

The findings of this study revealed that majority of the patients (77.5\%) showed excellent satisfaction with the quality of nursing care received during their stay on the ward.25(25.8\%) reported good satisfaction with the quality of nursing care received while only $1.7 \%$ rated quality of nursing care as poor. This agrees with a study on patient satisfaction with nursing care carried out by Muhodwa, Leshabari, Mwangwu, Mbembati and Ezekiel (2008) which showed that $3.5 \%$ rated satisfaction as poor, $18.0 \%$ of the respondents expressed good satisfaction while $78.5 \%$ of them rated their satisfaction with quality of nursing care as excellent.

\section{Assessing Patients' Satisfaction with Dimensions of Nursing Care}

The research findings show that in terms of several dimensions of nursing care patients had different levels of satisfaction. In the area of helpfulness, nurses were found to be very helpful with $7.5 \%$ rating them excellent, $52.5 \%$ rating them very good, $35.8 \%$ rating them good, $4.2 \%$ rating them fair and none rating them poor. Nursing staff response time was also rated very highly, the skills and competence of the nurses was also rated very good however in terms of providing privacy for patient the rating became more average. The dimension of giving discharge instruction was rated as unsatisfactory with $6.7 \%$ rating them excellent, $12.5 \%$ rating them very good, $30.0 \%$ rating good, $31.7 \%$ rating them fair and $19.1 \%$ rating them poor. The dimension of coordination of care was also rated very poorly in fact most patient commented that the nurses seemed to ignore them once they had been discharged. $2.5 \%$ rated them as excellent, $3.3 \%$ rated them very good, $12.5 \%$ rated them as good, and $27.5 \%$ rated them fair while the majority (54.2\%) rated their satisfaction with that dimension as very poor.

\section{Conclusion}

The results of the study emphasized the role of patient satisfaction as one of the indicators for measuring quality of nursing care and also their willingness to return to the same facility for their healthcare needs. Patient satisfaction is often used in planning and evaluation of care. It is therefore necessary for nurse administrators and policy makers to include patients' views and opinions in the planning and evaluation of care. In this study, factors that were found to affect patient satisfaction significantly are: quality of care, communication and information professional-technical skills and competence as well as environmental factions and not necessarily the socio demographic background of the patients. Nurses should therefore be made more sensitive to and aware of the importance of patients' feelings, opinions, right to information and autonomy. It is also clear that evaluating patient satisfaction should be constant so as to reformulate the baseline and to be able to assess interventions and changes in nursing care provision.

\section{Nursing Implication of Findings}

The findings of the study have implications for nursing practice, nursing education, nursing administration and nursing research.

\section{Nursing Practice}

The findings of the study indicate that there is need to evaluate quality nursing care for better improvement. All health care workers, especially nurses should be made aware of it by regular in-service training programs conducted to refresh and update knowledge and skill on different aspects of patients care. Evidenced based nursing practices can go a long way in improving the quality of nursing care delivered to the patients admitted in various units of hospital.

\section{Nursing Education}

This study highlighted the importance of nurses' professional technical skills and competence as critical to, and the backbone of, provision of quality care. The knowledge of patient feelings and expectations may be utilized in nursing education programs and curricula to create awareness and prepare nurses to better understand patients of feelings about care. It is also believed that nursing education programs should be able to raise awareness contributing to patients' vulnerability and poor-quality ssscare. The nursing curriculum of Medical-Surgical nursing should include learning experiences. a planned teaching program should be organized for staff nurses about quality care and nursing audit for appraisal of health care in workshops can be organized frequently to update the knowledge, skill and practices for nurses.

\section{Nursing Administration}

The nurse administrator plays vital role in nursing practice and education. To bring about any changes in nursing, administrator should take the responsibility and take up the challenges, which will improve, standard of care. The Patient satisfaction with nursing care quality questionnaire adapted by the researcher may be utilized by the ward supervisor or the chief nursing officers to assess the patients' satisfaction with nursing care. The Administrator should motivate the staff nurses, to learn new methods about providing quality care. The administrator should aware of resent research findings, professional conferences and in service education opportunities. 


\section{Nursing Research}

Patient satisfaction is very complex and even patients are not able to determine what constitutes patient satisfaction. It is therefore important that health care organizations take note of this study and embark on research investigating factors contributing to patient satisfaction with nursing care and report on how these factors affect patient satisfaction and quality of care. Nursing research is an essential part of nursing as it uplifts the profession and develops new nursing norms and a body of knowledge. It should be done on preparation of innovative methods of nursing care practices. Many more innovative studies can be conducted on patient satisfaction with nursing care using the research design, findings and the tool as avenues for further research. Conducting research studies on the different modalities will help to develop nursing knowledge and upliftment of the nursing profession

\section{Recommendations}

The results of the study showed knowledge regarding patient satisfaction from the patients' perspective of care encountered during their hospitalization. The results highlighted some of the experiences encountered by patients, how patients' perceived behavior or attitudes of nurses, how they were treated and how they wanted to be treated, how they wanted to be communicated with, how they valued nurse-patient relationship and finally how they perceived the organizational and environmental factors. It is upon this premise that the following recommendations have been made.

a) Each patient should be called after discharge for their opinion regarding satisfaction with nursing care while on admission.

b) Patients' opinion for improving quality of nursing care should be taken into considerations to improve the quality of nursing care.

c) Annual mandatory educational program for nurses should be established to updates their knowledge on patient satisfaction.

d) A program should be established to award nurses with quality nursing care per patient recommendation.

\section{References}

1. Morris J, Jahangir A, Sethi K (2013) Patient satisfaction: an emerging health policy issue. American Academy of Orthopedic Surgeons Now $7(6)$.

2. Aiken L, Clarke S, Sloane D (2013) Hospital nurse staffing and patient mortality, nurse burnout, and job dissatisfaction. JAMA 288: 1987-1993.

3. Wagner D, Bear M (2008) Patient satisfaction with nursing care: a concept analysis within a nursing framework. J Advanced Nursing 6: 1516.

4. Delbanco T (2006) Quality of care through the patient's eyes satisfaction surveys are just the start of an emerging science. British Medical J 313: 832-833.

5. Aiken LH, Sermeus W, Van den Heede,K, Sloane DM, Busse R, et al. (2012) Patient safety, satisfaction, and quality of hospital care: cross sectional surveys of nurses and patients in 12 countries in Europe and the United States British Medical Journal, pp. 344.
6. Crow R, Storey L, Page H (2013) The measurement of patient satisfaction: Implications for health service delivery through a systematic review of the conceptual, methodological and empirical literature. Health Technology Assessment 6: 32137-32140.

7. Lynn M, McMillen B, Sidani S (2007) Understanding and measuring patients' assessment of the quality of nursing care. Nursing Research 56: 159-166.

8. Rafii F, Hajinezhad E, Hamid H (2007) Nurse caring in Iran and its relationship with patient satisfaction Australian J Advanced Nursing 26(2): 75-84.

9. Cleary PD, McNeil BJ (1988) Patient Satisfaction as an Indicator of Quality Care. J Article of Inquiry 25(1): 25-36.

10. Thrasher, Purc Stephenson R (2008) Patient satisfaction with nurse practitioner care in emergency departments in Canada. Journal of the American Academy of Nurse Practitioners 20(5): 231-237.

11. Laschinger S, Hall M, Pedersen C, Almost J (2005) A psychometric analysis of the patient satisfaction with nursing care quality questionnaire an actionable approach to measuring patient satisfaction. J Nursing Care Quality 20(3): 220-230.

12. Woodside G, Frey L, Daly RT (1989) Linking service quality, customer satisfaction and behavioral intention. J Health Care Marketing 9(4): 5-17.

13. Findik Y, Unsar S, Sut N (2010). Patient satisfaction with nursing care and its relationship with patient characteristics. Nursing and Health Sciences 12(2): 162-169.

14. Linda Pelz (1982) Social psychological determinants of patients satisfaction. Social science and medicine 16: 583-586.

15. Ijeoma M, Ada N, Peace I, Akpati V (2011) Helpless patient satisfaction with quality of nursing care in federal territory hospitals, Enugu, Southeast, Nigeria. Int j nursing and midwifery; 3 [1]: 6-13.

16. O'Connor S, Shewchuk R, Carney L (1994) The great gap. J Health Care Marketing 14(2): 32-9.

17. Muntlin A, Gunningberg L, Carlsson M (2006) Patient's perception of care at an emergency department and identification of areas for quality Improvement. J Clinical Nursing 15(8): 1045-1056.

18. Lucero R, Lake T, Aiken H (2010) Nursing care quality and adverse events in U S hospitals. J clinical nursing 19(15-16): 2185-2195.

19. Watson J (2009) Caring science and human caring theory: transforming personal and professional practices of nursing and health care. J Human Health and Services Administration 31(4): 466-482.

20. Chitty K (2005) Defining nursing: Harder than it seems. In T Wilhelm, J Downing (Eds). Professional Nursing Concepts \& Challenges $\left(4^{\text {th }}\right.$ edn.). St Louis, MI: Elsevier Sanders.

21. Lynn MR, McMillen BJ, Sidani S (2007) Understanding and Measuring Patients' Assessment of the Quality of Nursing Care J Nursing Research 15(3): 159-166.

22. Liu J, Mok E, Wong T (2006) Caring in nursing: investigating the meaning of caring from the perspective of cancer patients in Beijing, China. J Clinical Nursing 15: 188-196. 
ISSN: 2574-1241

DOI: 10.26717/BJSTR.2019.17.002941

Olowe A Folami F. Biomed J Sci \& Tech Res

(c) (P) This work is licensed under Creative

Submission Link: https://biomedres.us/submit-manuscript.php

$\begin{array}{ll}\text { BIOMEDICAL } & \text { Assets of Publishing with us } \\ \text { RESEARCHES } & \text { - Global archiving of articles } \\ \text { - Immediate, unrestricted online access } \\ \text { - Rigorous Peer Review Process } \\ \text { - Auttps://biomedres.us/ }\end{array}$

